
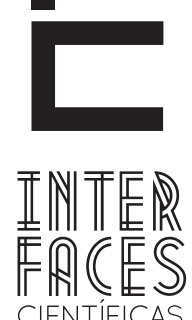

HUMANASE SOCIAIS

ISSN IMPRESSO 2316-3348

E-ISSN 2316-3801

DOI - 10.17564/2316-3801.2019v7n3p33-46

\title{
POLITICAS PÚBLICAS DO CENTRO DE APOIO E ACOMPANHAMENTO À INCLUSÃO: INTEGRAÇÃO OU INCLUSÃO ESCOLAR?
}

\author{
PUBLIC POLICIES OF THE CENTER FOR INCLUSION SUPPORT AND MONITORING: INTEGRATION OR SCHOOL INCLUSION?
}

POLÍTICAS PÚBLICAS DEL CENTRO DE APOYO Y SEGUIMIENTO DE LA INCLUSIÓN: ¿INTEGRACIÓN O INCLUSIÓN EDUCATIVA?

Andreia Patricia de Oliveira Huertas ${ }^{1}$

Heloisa Candia Hollnagel ${ }^{3}$
Maria Camila Florêncio da Silva²

tada pela bibliografia específica sobre o tema. Os resultados indicam que as políticas de atendimento do CEFAI se coadunam à perspectiva de educação inclusiva, a qual garante o acesso e permanência das crianças e jovens com necessidades educacionais especiais em salas de aulas regulares de ensino sem, contudo, ser uma prática inteiramente consolidada.

\section{PALAVRAS-CHAVE}

Políticas Públicas Educacionais. Plano Nacional de Educação. Educação Especial. Inclusão Escolar. 


\section{ABSTRACT}

Goal number 4 of the National Education Plan in Brazil (2014-2024) aims to ensure the educational rights of persons with disabilities, to inclusive education system warranty and public or covenant specialized services. The purpose of this article is to study the implementation conditions of public policies in Special Education developed by the Training and Monitoring Inclusion Center CEFAI, the Municipal Secretary of Education of São Paulo/SP, in order to identify principles and characteristics that indicate practices integration and school inclusion. To achieve this, the analysis of official documents relating to this institution was conducted, supplemented by specific bibliography on the subject. The results indicate that care policies of CEFAI are consistent with inclusive education perspective, which guarantees access and permanence of children and young people with special educational needs in regular classrooms teaching. Nevertheless it is still not a fully consolidated practice.

\section{KEYWORDS}

Educational Public Policy. National Education Plan. Special Education. School Inclusion.

\section{RESUMEN}

La meta número 4 del Plan Nacional de Educación en Brasil (2014-2024) tiene por objetivo garantizar los derechos a la educación de las personas con discapacidad, incluido a la garantía del sistema de educación y los servicios especializados, públicos o con licencia. El propósito de este artículo es estudiar las condiciones de implementación de las políticas públicas en Educación Especial desarrollado por Centro de Inclusión y Capacitación - CEFAI, Secretaria Municipal de Educación de São Paulo/SP, para identificar los principios y características que indican la integración de las prácticas y la inclusión educativa. Con este fin, se llevó a cabo el análisis de los documentos oficiales relativos a esta institución, complementado con bibliografía específica sobre el tema. Los resultados indican que las políticas de atención del CEFAI son consistentes con la perspectiva de la educación inclusiva, que garantiza el acceso y la permanencia de los niños y jóvenes con necesidades educativas especiales en la enseñanza de las aulas regulares. Sin embargo, no es una práctica plenamente consolidada.

\section{PALABRAS CLAVE}

Política Pública Educativa. Plan Nacional de Educación. Educación especial. Inclusión educativa. 


\section{INTRODUÇ̄̃̃O}

No ano de 2014, passou a vigorar o novo Plano Nacional de Educação no Brasil (Lei 13.005/2014) que, a partir do debate com vários segmentos da sociedade civil organizada, estabeleceu vinte grandes metas para os próximos dez anos. Um grupo de metas diz respeito especificamente à redução das desigualdades e à valorização da diversidade, caminhos imprescindíveis para a equidade, dentre estas a Meta 4 pretende:

Meta 4: universalizar, para a população de 4 (quatro) a 17 (dezessete) anos com deficiência, transtornos globais do desenvolvimento e altas habilidades ou superdotação, o acesso à educação básica e ao atendimento educacional especializado, preferencialmente na rede regular de ensino, com a garantia de sistema educacional inclusivo, de salas de recursos multifuncionais, classes, escolas ou serviços especializados, públicos ou conveniados. (BRASIL, 2014, on-line).

Em uma análise histórica, a Educação Especial possui dois momentos distintos: o primeiro, caracterizado pela ação substitutiva/paralela ao ensino regular e o segundo, representado pela sua ação complementar/transversal ao ensino regular. A estratégia 1.11 da Meta 1 do PNE (2014), de atender, no mínimo, $50 \%$ (cinquenta por cento) das crianças de até 3 (três) anos até o final da vigência deste se compromete a

\section{[...] priorizar o acesso à educação infantil e fomentar a oferta do atendimento educacional especializado com- plementar e suplementar aos (às) alunos (as) com defi- ciência, transtornos globais do desenvolvimento e altas habilidades ou superdotação, assegurando a educação bilíngue para crianças surdas e a transversalidade da educação especial nessa etapa da educação básica.}

Entretanto, estabelecer as condições necessárias para garantir o direito à educação deste grupo significa "analisar as propostas de inclusão escolar destes alunos, principalmente sobre as estratégias de sua escolarização nas classes comuns das escolas regulares e sobre a realidade da atual política nacional de educação especial na perspectiva inclusiva" (MATOS; MENDES, 2014, p. 37).
Não obstante, ao longo desta caminhada para viabilizar a proposta de uma política de educação inclusiva no Brasil, ocorreram também mudanças nos conceitos de deficiência no meio educacional, inclusive em sua nomenclatura, a qual passa a ser denominada como "necessidades educacionais especiais", expressão que pode ser traduzida como qualquer dificuldade de aprendizagem decorrente não somente de fatores físicos, mas também de ordem econômica, social e cultural. De acordo com o Ministério da Educação e Cultura, este termo surgiu para evitar efeitos negativos de outras expressões utilizadas no contexto educacional, como excepcionais, deficientes, superdotados, dentre outros (BRASIL, 1999).

No caso do município de São Paulo, desde 2004, por meio do decreto municipal 45.415/2004 e da portaria 5.718/2004, a política de atendimento a alunos com necessidades educacionais especiais no município de São Paulo está a cargo do Centro de Formação e Acompanhamento à Inclusão (CEFAI), o qual está em funcionamento em todas as suas treze diretorias de ensino nas quais se subdivide sua rede de atendimento aos alunos.

Este trabalho, assim, estuda as condições de implantação das políticas públicas em Educação Especial por meio da metodologia qualitativa, combinando a análise com a documental, aqui entendida como foi realizado um levantamento de documentos oficiais (leis federais e municipais) referentes às questões de inclusão e integração escolar de alunos portadores de necessidades especiais.

Identificamos na literatura especializada textos que diferenciavam políticas de integração, que consiste na inserção de alunos com necessidades educacionais especiais nas escolas regulares e na Educação Especial de forma segregadora, de políticas de inclusão, as quais questionam as políticas e a organização da educação especial e do próprio conceito de integração, defendendo a inserção escolar de forma radical, completa e sistemática.

Enquanto que numa perspectiva de integração a escola não muda e sim os alunos devem se adaptar a ela, a de inclusão exige uma mudança em todo para- 
digma educacional, visto que almeja alcançar todos os alunos com ou sem dificuldade de aprendizado. Isso requer não só mudanças em estruturas físicas, como também nas matrizes curriculares de ensino e de conceitos e pré-conceitos historicamente construídos (MANTOAN, 2006).

Desta forma, buscamos verificar a presença das características de inclusão e de integração nas políticas públicas promovidas pelo CEFAI com vistas a responder se estas estariam mais próximas de um modelo ou outro e, do mesmo modo, constatar quais os princípios que orientam essas ações.

\section{POLLITICAS PÚBLICAS E EDUCAÇ̃̃O INCLUSIVA}

Embora o objetivo deste trabalho tenha foco nos princípios e as características que indicam práticas de integração ou de inclusão escolar, sendo estes dois paradigmas opostos de práticas sobre inserção das pessoas com deficiência que se situam em um campo da literatura a parte, tais práticas estão situadas no campo das Políticas Públicas. No caso em tela, da Política de Educação do município de São Paulo. Por este motivo, é importante situar o leitor sobre o que os autores deste trabalho entendem por Política Pública.

Sobre isto, é importante dizer que "não existe uma única, nem melhor, definição sobre o que seja política pública" (SOUZA, 2006, p. 24). No entanto, como elucida Souza (2006) em uma das mais citadas revisões de literatura sobre Políticas Públicas no Brasil, "as definições de políticas públicas, mesmo as minimalistas, guiam o nosso olhar para o locus onde os embates em torno de interesses, preferências e ideias se desenvolvem, isto é, os governos" (SOUZA, 2006, p. 25).

Por este motivo, assim como Farah (2004, p. 27), entendemos Política Pública como "um curso de ação do Estado, orientado por determinados objetivos, refletindo ou traduzindo um jogo de interesses", que permite "resumir política pública como o campo do conhecimento que busca, ao mesmo tempo, "colocar o governo em ação" e/ou analisar essa ação (variável independente) e, quando necessário, propor mudan- ças no rumo ou curso dessas ações (variável dependente)" (SOUZA, 2006, p. 26).

0 curso de ação analisado por este trabalho é o das práticas do CEFAI que guardam consigo uma concepção do problema reconhecido pela agenda governamental (KINGDON, 1995). Dizer se tais práticas estão mais próximas do paradigma da integração ou da inclusão, é dizer, no campo das Políticas Públicas, qual a concepção do problema que ingressou na agenda de decisão do governo municipal de São Paulo e que se reflete nas ações da Política do CEFAI. É preciso então compreender que paradigmas são esses.

O paradigma da integração escolar e inclusão escolar, segundo Mantoan (2015), por meio da integração escolar o aluno tem várias possibilidades educacionais, que vão desde a inserção no ensino regular até o ensino em escolas especializadas:

Na integração escolar, nem todos os alunos com deficiência cabem nas turmas de ensino comum, pois há uma seleção prévia dos que estão aptos à inserção. Para esses casos, são indicados: a individualização dos programas escolares; currículos adaptados; avaliações especiais; redução dos objetivos educacionais para compensar as dificuldades de aprender. (MANTOAN, 2015, p. 27).

Já no que se refere à inclusão, esta seria, ainda segundo autora, incompatível com a integração porque pressupõe a inserção de forma radical de todos os alunos na escola, com todos, frequentando as salas de aula do ensino regular:

\begin{abstract}
As escolas inclusivas atendem a todos os alunos sem discriminar, sem trabalhar à parte com alguns deles, sem estabelecer regras específicas para planejar, ensinar e avaliar alguns por meio de currículos adaptados, atividades diferenciadas, avaliação simplificada em seus objetivos. (MANTOAN 2015, p. 28).
\end{abstract}

Sanches e Teodoro (2006), analisando as principais diferenças conceituais no que concerne à trajetória de transição da integração para a inclusão escolar, apresentam uma comparação entre três autores de sólida trajetória na área para, didaticamente, elencar as diferenças entre as duas concepções apresentadas no Quadro 1: 
Quadro 1 - Características da Integração Escolar e da Inclusão Escolar

\begin{tabular}{|c|c|c|}
\hline & INTEGRAÇÃO ESCOLAR EDUCAÇÃO ESPECIAL & INCLUSÃO ESCOLAR EDUCAÇÃO INCLUSIVA \\
\hline \multirow{4}{*}{ 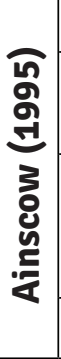 } & Das necessidades educativas especiais & À educação para todos \\
\hline & $\begin{array}{l}\text { Das medidas complementares para responder aos } \\
\text { alunos especiais }\end{array}$ & $\begin{array}{c}\text { À resposta às necessidades educativas de todas as } \\
\text { crianças e jovens }\end{array}$ \\
\hline & $\begin{array}{c}\text { De um sistema educativo que se mantém inalterável } \\
\text { nas suas linhas gerais }\end{array}$ & $\begin{array}{c}\text { À reestruturação das escolas: mudanças metodoló- } \\
\text { gicas e organizacionais; sucesso nas aprendizagens } \\
\text { para todos alunos }\end{array}$ \\
\hline & Da perspectiva centrada na criança & Á perspectiva centrada no currículo \\
\hline \multirow{6}{*}{ 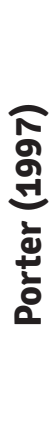 } & Da Abordagem tradicional & À abordagem inclusiva \\
\hline & Da focalização no aluno & À focalização na classe \\
\hline & Da avaliação dos alunos por especialistas & À avaliação das condições de ensino/aprendizagem \\
\hline & $\begin{array}{c}\text { Dos resultados da avaliação traduzidos em diagnós- } \\
\text { tico/prescrição }\end{array}$ & À resolução cooperativa de problemas \\
\hline & Do programa para os alunos & Às estratégias para os professores \\
\hline & Da colocação num programa apropriado & À adaptação e apoio na classe regular \\
\hline \multirow{4}{*}{ 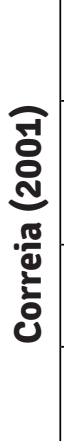 } & Da integração física e social & $\begin{array}{c}\text { À integração cognitiva } \\
\text { À cultura da escola e da sala de aula }\end{array}$ \\
\hline & Da homogeneidade (aluno médio) & $\begin{array}{c}\text { À diversidade como princípio e fim } \\
\text { Ao objetivo primeiro: desenvolvimento global dos } \\
\text { alunos }\end{array}$ \\
\hline & Dos alunos com necessidades educativas especiais & A todos os alunos \\
\hline & $\begin{array}{l}\text { Da entrada de alguém na corrente principal: ser } \\
\text { uma parte do todo }\end{array}$ & A fazer parte do todo \\
\hline
\end{tabular}

Fonte: Adaptado pelos autores de: Sanches e Teodoro (2006).

Segundo Mitler (2003), baseado no Index for Inclusion: Developing Learning and Participation in Schools, documento britânico para a implantação de uma educação inclusiva, algumas estratégias são fundamentais para a efetivação de uma educação inclusiva, dentre as quais se destacam a participação de toda a comunidade escolar nas diretrizes curriculares; o uso de registros como ferramenta de avaliação dos alunos; a aprendizagem e o ensino colaborativos; o apoio profissional e de especialistas.

No que concerne à avaliação escolar, para que seus processos e resultados não se transformem em instrumentos de exclusão dentro das Unidades Educacionais, sugere-se que as práticas avaliativas considerem o acesso e a participação nas experiências de aprendizagem, como o registro de aquisição, que in- 
clui os interesses dentro e fora das escolas. Já em relação à aprendizagem, ela consistiria na reunião dos alunos em pequenos grupos que lhes permitem dividir tarefas e compartilhar o que precisam aprender com a mediação do professor; e o ensino colaborativo trata-se da presença de um professor de apoio na sala de aula para auxiliar o professor regente.

Carvalho (2011) também aborda os conflitos entre os conceitos da integração escolar e os da inclusão escolar. Para ela, a integração está inserida no processo de inclusão e a escola inclusiva só é possível por meio da remoção de barreiras construídas socialmente ao longo da história da Educação Especial:

As barreiras para a aprendizagem e para a participação dizem respeito à construção de conhecimentos, bem como as interações dos aprendizes entre si, com seus educadores, familiares e com os objetos do conhecimento e da cultura. Remover barreiras implica um trabalho coletivo de facilitação do aprender a aprender, aprender a fazer, aprender a ser e aprender a viver junto. (CARVALHO, 2011, p. 73)

A realização de estudos que analisem as políticas públicas de atendimento especializado pode ser uma das contribuições para a melhoria da qualidade do ensino oferecido aos alunos com necessidades educacionais especiais. É nessa perspectiva que se insere a presente pesquisa que examinará as políticas públicas municipais desenvolvidas pelo CEFAI, de forma a verificar se são ações direcionadas numa perspectiva inclusiva ou de integração.

\section{CENTRO DE FORMAÇ̃̃O E ACOMPANHAMENTO À INCLUSÃO (CEFAI): LEGISLAÇ̃̃OE DOCUMENTOS OFICIAIS}

O decreto municipal 45.415/2004 efetivou as políticas públicas em Educação Especial, estabelecendo as diretrizes para a política de atendimento às crianças, jovens e adultos com necessidades especiais no sistema municipal de ensino. Assegura, dentre outras coisas, matricula de todo e qualquer educando nas classes comuns, "visto que reconhecida, considerada, respeitada e valorizada a diversidade humana, sendo vedada qualquer forma de discriminação".

\begin{abstract}
$\S 1^{\circ}$. Entende-se por crianças, adolescentes, jovens e adultos com necessidades educacionais especiais aqueles cujas necessidades educacionais se relacionem com diferenças determinadas, ou não, por deficiências, limitações, condições e/ou disfunções no processo de desenvolvimento e altas habilidades/superdotação. (SÃO PAULO, 2004a, on-line).
\end{abstract}

Ao definir que as pessoas com necessidades educacionais especiais podem ou não ter alguma limitação causadas por deficiências diversas, a rede municipal de educação amplia o atendimento para aqueles alunos que apresentam dificuldades de aprendizagem relacionadas às condições familiar, social e cultural.

De forma parecida à Lei de Diretrizes e Bases da Educação Nacional (LDBEN)/96, o decreto 45.415/2004 contempla a oferta da Educação Especial em unidades de ensino regulares e especializadas. Para tal, cria o Centro de Formação e Acompanhamento à Inclusão (CEFAI), o Professor de Apoio e Acompanhamento à Inclusão (PAAI), e a Sala de Apoio e Acompanhamento à Inclusão (SAAI). Esses serviços junto aos prestados pelas Escolas Municipais de Educação Bilíngue para Surdos (EMEBS) configuram a rede de apoio à educação especial na cidade de São Paulo e devem ser oferecidos em caráter transitório, na perspectiva de se garantir a permanência e/ou retorno à classe comum.

O CEFAI é responsável por desenvolver ações de formação permanente aos profissionais das Unidades Educacionais, por meio de oficinas, reuniões, palestras, cursos e outros; acompanhar os educandos com necessidades educacionais especiais, por meio de visitas às escolas e reuniões com familiares; disponibilizar recursos materiais; organizar e a avaliar as ações formativas nas Unidades Educacionais; e programar as diretrizes relativas às políticas de inclusão. Compõem o CEFAI, profissionais da Diretoria de Orientação Técnico-Pedagógica (DOT-P) e Professores de Apoio e Acompanhamento à Inclusão (PAAI), com es- 
pecialização e/ou habilitação em Educação Especial ou em uma de suas áreas: deficiência física, mental, visual, auditiva e múltipla (SÃO PAULO, 2004b).

O PAAI realiza o serviço itinerante de apoio e acompanhamento pedagógico à Comunidade Educativa, também é encarregado de efetuar atendimento individual ou em pequenos grupos de educandos; colaborar com o professor regente da classe comum no desenvolvimento de mediações pedagógicas; orientar as famílias dos alunos com necessidades educacionais especiais (SÃO PAULO, 2004).

O SAAI é o serviço realizado nas próprias unidades de ensino e representam o serviço complementar ou exclusivo de atendimento ao aluno com deficiência, nos termos da Portaria 5.718/2004:

Art. $9^{\circ}$ - As Salas de Apoio e Acompanhamento à Inclusão - SAAI, instaladas nas Unidades Educacionais da Rede Municipal de Ensino, serão destinadas ao apoio pedagógico especializado de caráter complementar, suplementar ou exclusivo de crianças, adolescentes, jovens e adultos com deficiência mental, visual, auditiva (surdez múltipla), surdocegueira, transtornos globais do desenvolvimento e superdotação (altas habilidades), desde que identificada e justificada a necessidade deste serviço, por meio da realização de avaliação educacional do processo ensino e aprendizagem. (SÃO PAULO, 2004b, on-line).

Esse espaço se constitui como um atendimento educacional especializado, serviço que pode ser definido, em linhas gerais, como uma ação que objetiva contribuir para a inclusão do educando de forma alinhada ao projeto pedagógico da escola com vistas a proporcionar a aprendizagem desses alunos, o qual, se bem estruturado, contribui de forma significativa para a permanência do educando com deficiência na escola (BARBOSA; FUMES, 2016). A Unidade Educacional é quem requisita a instalação desta sala e disponibiliza o serviço para os alunos da própria escola ou de outras Unidades da Rede Municipal de Ensino de seu entorno, onde não exista tal atendimento (SÃO PAULO, 2016b).

O decreto municipal 51.788/2010 fortaleceu a política em educação especial no município de São Paulo com a instituição do Programa Inclui, que tem como objetivo integrar diversos projetos específicos, “constituindo uma rede de apoio ao aluno, à escola e à família, por meio de suportes e serviços especializados que viabilizem o acompanhamento da trajetória escolar e do processo de aprendizagem do aluno" (SÃO PAULO, 2010, on-line).

O Projeto Rede oferece apoio intensivo na locomoção, alimentação e higiene aos alunos com limitações físicas. Por outro lado, o Projeto Apoiar amplia as instalações das SAAI e do módulo de PAAI, além de oferecer estagiários de pedagogia ao CEFAI para atuar nas Unidades Educacionais.

Por intermédio do Projeto Rede, os AVE são capacitados para acompanhar em média quatro alunos (por turno) com deficiências severas, que não têm autonomia para alimentar-se, fazer a própria higiene ou se locomover. Este profissional deve permanecer durante o período de aula do aluno, fora da sala, aguardando que seja solicitado para realizar suas funções exclusivamente no que se refere aos cuidados do aluno (SÃO PAULO, 2013). Além disso, 42 fisioterapeutas e terapeutas ocupacionais visitam mensalmente as Unidades Educacionais para avaliação, prescrição de mobiliário adaptado e orientação ao trabalho dos AVE (SÃO PAULO, 2016b).

Por sua vez, os estagiários de Pedagogia, no âmbito do Projeto Apoiar, auxiliam o professor na rotina da sala de aula, oferecendo assistência individual durante as atividades para aqueles alunos que evidenciarem maior necessidade de apoio e auxílio a pequenos grupos de alunos em atividades de recreação, roda da leitura, roda da conversa, dentre outras (SÃO PAULO, 2013).

Um levantamento realizado pelos 13 Núcleos Multidisciplinares - equipe de especialistas, fonoaudiólogos, psicólogos e assistentes sociais, que atuam junto ao CEFAI - revelou que $50 \%$ dos estudantes encaminhados para a avaliação que identifica a hipótese de deficiência, apresentavam outras questões relativas a dificuldades significativas de aprendizagem e a vulnerabilidade social (SÃO PAULO, 2016b). Deste modo, em 2014, a SME/SP por meio da Portaria 6.566/14 implantou o Núcleo de Apoio e Acompanhamento para a Aprendizagem (NAAPA) nas 13 DRE, com o propósito 
de atender a demanda de educandos com problemas na escolarização, melhorar os resultados das aprendizagens e garantir uma rede de proteção de proteção social, efetivando a articulação entre os serviços de educação, saúde, assistência social. Essas ações visam "garantir a continuidade do trabalho desenvolvido pelo Núcleo Multidisciplinar em apoio ao CEFAI, às equipes educacionais e às famílias dos educandos público alvo da educação especial”. (SÃO PAULO, 2014).

\section{ANÁLISE E RESULTADOS DAS ACÕ̃ES DO CEFAI}

Diante da análise documental realizada nas legislações que criaram e fortaleceram CEFAI, verificou-se três vertentes em relação à organização das políticas públicas para a promoção da inclusão. A primeira, refere-se às questões de dimensão legal, normativa ou política, que tratam das garantias para o acesso e permanência das pessoas com necessidades educacionais especiais no ensino regular; a segunda, àquelas de dimensão pedagógica, o ato de ensinar e aprender, a avaliação e a formação continuada; e a terceira, àquelas voltadas aos serviços médicos e assistenciais.

Como constatado no tópico anterior, foram publicados decretos e portarias que respaldaram as políticas públicas voltadas aos alunos com necessidades educacionais especiais, como a criação e regulamentação das SAAI e dos PAAI (Decreto 45.415/04 e Portaria 5.718/04), e a instituição do Programa Inclui (Decreto 51.778/10) e do NAAPA (Portaria 6.566/14).

Quanto ao aspecto pedagógico, o CEFAI destaca-se pela sua atuação junto às escolas, apoiando diretamente alunos, famílias, professores e gestores; pela formação continuada realizada com a equipe escolar; e pela oferta de materiais pedagógicos especializados e recursos humanos (estagiárias de pedagogia e as Auxiliares de Vida Escolar - AVE).

Em seu estudo sobre as estratégias de educação inclusiva adotadas na Inglaterra, Mittler (2003) cita o ensino colaborativo, com a presença de um segundo professor na sala de aula para apoiar as crianças com dificuldade de aprendizado e o professor regen- te. As práticas de ensino colaborativo na rede municipal de São Paulo configuram-se na rede de apoio e assistência aos alunos com necessidades educacionais especiais com as ações do CEFAl articuladas com as ações do Programa Inclui.

A partir dessa rede, foi verificado que o CEFAI dispõe de estagiários na área de pedagogia para acompanhar o aprendizado dos alunos com limitações severas associadas às deficiências mental, visual, auditiva e múltipla. Em relação à deficiência física, - CEFAI solicita ao Inclui a necessidade de AVE para auxiliar nos cuidados de alimentação, higiene e locomoção do aluno. Além dos estagiários de pedagogia e dos auxiliares, os PAAI também atuam diretamente nas escolas junto aos professores regentes, com orientações didáticas, produções de materiais didáticos adequados e acompanhamento aos alunos com necessidades educacionais especiais.

Outro aspecto importante foi a redefinição do conceito de avaliação, que fosse compatível com as novas diretrizes curriculares, prevendo a participação da família nos processos de avaliação e aprendizagem. O CEFAI acompanha essas avaliações realizadas nas escolas e com os alunos com necessidades educacionais especiais.

Todas essas ações, mudanças nos conceitos de Educação Especial e de avaliação, ensino colaborativo, oferecimento de recursos materiais e pessoais para atendimento e desenvolvimento pleno da pessoa com necessidades educacionais especiais são experiências de inclusão escolar (MITTLER, 2003).

Para Mantoan (2015), a inclusão não prevê utilização de práticas ou métodos de ensino diferenciados para atender as especificidades de alguns alunos. Na verdade, a escola de qualidade se traduz em espaços educativos nos quais crianças e jovens se desenvolvem por meio da convivência e das relações socioafetivas que se estabelecem entre os membros da comunidade escolar.

Escolas assim concebidas não excluem nenhum aluno de suas salas, de seus programas, de suas aulas, das atividades e do convívio escolar mais amplo. São contextos educacionais em que todos têm a possibilidade 
de aprender frequentando uma mesma e única turma. (MANTOAN, 2015, p. 69).

Quanto aos serviços médicos e terapêuticos - fonoaudiólogos, fisioterapeutas, psicólogos e psiquiatras - oferecidos em parcerias com as áreas da saúde, da assistência social e com as redes conveniadas não há um consenso entre os teóricos se representam práticas segregadoras ou inclusivas. Normalmente, a integração é associada ao modelo médico que vê a deficiência da pessoa como um problema que deve ser tratado, assim, torna-o um indivíduo mais próximo do chamado "normal". Já a inclusão refere-se ao modelo social da deficiência e considera que os problemas dos deficientes foram determinados socialmente, respeitando os diferentes tipos e tempos de aprendizagem, "o que é almejado é a igualdade de oportunidades não a igualdade que nega a diversidade" (SAMPAIO; SAMPAIO, 2009, p. 41).
Ao se debruçar sobre a legislação brasileira em relação às políticas públicas de Educação Especial, Mantoan (2015) afirma que todo e qualquer instrumento necessário à eliminação de barreiras - como o ensino da Língua Brasileira de Sinais (LIBRAS) e do código braile, o uso de recursos materiais e de tecnologias assistivas - precisa estar disponível nas escolas regulares (MANTOAN, 2015).

De acordo com os estudos de Mittler (2003) e de Mantoan (2015) toda ação educativa desenvolvida fora do ambiente da sala de aula regular poderia, em tese, se configurar em uma prática segregadora de ensino, ou seja, de integração escolar, bem como as ações voltadas ao apoio médico e social. Para se ter mais clareza da natureza das políticas públicas em Educação Especial desenvolvidas pelo CEFAI, foi organizado o Quadro 2 abaixo, indicando quais são as ações segregadoras e as ações inclusivas a partir dessas considerações teóricas.

Quadro2 - Ações do CEFAl e da Rede de Apoio à Inclusão

\begin{tabular}{|c|c|}
\hline SEGREGRAÇÃO ESCOLAR & INCLUSÃO ESCOLAR \\
\hline EMEBS $^{1}$ & Formação dos Docentes \\
\hline SAAI ${ }^{2}$ & Encontros com a família \\
\hline Redes Conveniadas (Instituição LARAMARA) ${ }^{3}$ & Materiais de apoio \\
\hline Parcerias com a Saúde ( CAPS, UBS, NASF) ${ }^{4}$ & PAAls \\
\hline Parcerias com a Assistência Social (CRAS, CCA, CREAS) $)^{5}$ & Estagiários Pedagogia / AVE \\
\hline
\end{tabular}

Fonte: Elaborado pelos autores

EMEBS - Escolas Municipais de Educação Bilíngue para Surdos (EMEBS)

SAAI- Sala de Apoio e Acompanhamento à Inclusão (SAAI).

LARAMARA: Associação Brasileira de Assistência ao Deficiente Visual

CAPS - Centro de Atenção Psicossocial; UBS - Unidade Básica de Saúde; NASF - Núcleo de Apoio à Saúde da Família.

CRAS - Centro de Referência de Assistência Social (para famílias em situação de vulnerabilidade e risco pessoal); CCA - Centro para Crianças e Adolescentes (oficinas e atividades recreativas); CREAS - Centro de Referência Especializado de Assistência Social (para indivíduos que estejam passando por violação de direitos humanos).

O Programa de Metas, desenvolvido para o período de 2013 a 2016, estabelece como a Meta 54 a revitalização dos CEFAI, de forma a proporcionar formação para os professores e acompanhamento aos alunos com deficiência matriculados na rede municipal de ensino. Em consulta aos dados mais atuais sobre a 
referida meta, o portal indica que ela foi plenamente atingida e superada $(105,2 \%)$ tendo como resultados, com base em março de 2016, os dois itens a seguir:

\begin{abstract}
Formação oferecida aos professores especialistas e aos das classes regulares e demais profissionais da educação: mais de 26.000 vagas em cursos optativos e em nível de pós-graduação aos profissionais da Rede Municipal de Ensino até dez/2015; Ampliação da oferta do Atendimento Educacional Especializado - AEE com a instalação de novas Salas de Apoio e Acompanhamento à Inclusão/SAAI: Criação de 152 SAAI, representando uma ampliação de $39,7 \%$ de oferta do serviço. (SÃO PAULO, 2016a, on-line).
\end{abstract}

Observa-se pelas ações da Secretaria Municipal de Educação uma constante reformulação nas ações de atendimento educacional especializado e o tema constar no Plano de Metas da gestão de Fernando Haddad (2012-2016) é um indicativo de sensibilização ao tema. Demonstra, sobretudo, a preocupação da rede municipal de ensino de São Paulo em atender uma demanda cada vez maior de alunos com necessidades educacionais especiais de forma inclusiva.

Ao trazer a questão para o campo de Políticas Públicas isto quer dizer que diferentes concepções sobre o problema entraram na agenda governamental (KINGDON, 1995) e fizeram parte da formulação da Política de Educação para pessoas com deficiência no município de São Paulo. Isto pode ter se dado pelo o fato de tal agenda ter atravessado diferentes gestões governamentais no município ${ }^{4}$, influenciando assim as práticas governamentais em curso que buscam lidar com este grande desafio de garantir a educação à estas pessoas em condições de vulnerabilidade.

Além disso, diversos autores apontam as dificuldades frente às "políticas educacionais e os modos de financiamento da educação [...] por isso, a educação para todos não é uma questão que se refere apenas ao âmbito da educação" (LAPLANE, 2004, p. 5), sendo

4 Desde a gestão da Prefeita Marta Suplicy $(2000$ - 2004) do Partido do Trabalhadores quando do foi editado tal decreto em 2004, passando pela gestão de José Serra (2005 - 2007) e Gilberto Kassab (2005-2012) do Partido da Social Democracia Brasileira e dos Democratas, respectivamente, até a gestão de Fernando Haddad do Partido dos Trabalhadores (2013 - até o presente momento). necessária uma articulação política entre a legislação e as providências administrativas e orçamentárias que possam garantir no cotidiano o prescrito em lei (OLIVEIRA; DRAGO, 2012). Cabe destacar que a SME tem desenvolvido várias ações no sentido de uma aproximação entre a lei e o cotidiano, principalmente no caso da Educação Inclusiva.

O Programa Inclui, fundamentado na democratização qualitativa da educação e a construção de uma escola para todos, contribui para aumentar as possibilidades de aprendizagem a todo e qualquer aluno, independentemente de suas condições biopsicossociais. Entretanto, sabe-se que as transformações da escola dependem de um compromisso coletivo de professores, gestores, pais e da sociedade em geral.

\section{CONSIDERACÕES FINAIS}

A pesquisa demonstrou que a legislação paulistana está adiante do que estabelece a Lei de Diretrizes e Bases da Educação Nacional - LDBN/96 em relação à inserção das pessoas com necessidades educacionais especiais em salas de aulas regulares, visto que supera o "preferencialmente" da legislação federal, evitando assim subjetivismos na interpretação de quando o aluno deve ser matriculado ou não no ensino regular e enfatiza, desde 2004, que todos os alunos deverão ser matriculados na sala comum e, quando necessário, receberão atendimento em classes exclusivas de forma transitória.

Igualmente, foi possível sistematizar as políticas públicas em Educação Especial e identificar as ações de natureza inclusiva e de integração escolar. De acordo com o referencial teórico, as escolas especializadas, os serviços segregados, a possibilidade de os educandos migrarem do ensino regular às escolas especiais e outras alternativas de atendimento diferenciado são características da integração escolar. As SAAI e as EMEBS representam o ensino especializado, de caráter transitório, ou seja, um ensino segregado, distante de uma educação inclusiva, mas que ainda se faz necessário para casos específicos. 
O estudo da documentação revelou que o Decreto 45.415/04 e seus desdobramentos fortaleceram o CEFAl e a rede de apoio a uma educação de orientação inclusiva, mas ainda assim oferecem alguns serviços especializados em educação especial, como atendimento suplementar ou exclusivo em SAAI e em EMEBS.

Enquanto alguns defendem ações diferenciadas para propor igualdade de oportunidades, outros apregoam que a inclusão não prevê utilização de práticas diferenciadas e que os alunos devem aprender dentro dos seus limites. Na verdade, o que a análise do referencial teórico mostrou é que diferentes concepções do problema ingressaram na agenda governamental e influenciam de formas distintas as práticas governamentais, ou seja, as alternativas da Política para resolver o problema que foram aqui representadas pelos paradigmas da integração versus inclusão.

Neste sentido, emergiu da documentação analisada a constatação de que, permeando as diversas gestões recentes da prefeitura de São Paulo e de secretários de Educação, há uma clara preocupação da rede municipal de ensino no sentido de promover a autonomia dos educandos sob sua responsabilidade. As práticas do CEFAI caminham, nesse sentido, em direção à inclusão em contraposição, sempre que possível, à integração. Entretanto, torna-se necessária uma mudança não apenas na estrutura física das escolas, mas principalmente no comportamento da comunidade escolar para, de fato, termos uma escola realmente inclusiva.

\section{REFERÊNCIAS}

BRASIL. Lei Federal no 9.394/96, de 20 de dezembro de 1996. Lei de Diretrizes e Bases da Educação Nacional. Brasília, Diário Oficial da União, de 23 de dezembro de 1996.

BRASIL. Ministério da Educação e Cultura - MEC. Parâmetros Curriculares Nacionais. Adaptações Curriculares. Estratégias para a educação de alunos com necessidades educacionais especiais. Brasília, 1999.
BRASIL. Lei $\mathbf{n}^{\mathbf{0}} \mathbf{7 . 8 5 3}$, de 24 de outubro de 1989. Dispõe sobre 0 apoio às pessoas portadoras de deficiência, sua integração social, sobre a Coordenadoria Nacional para Integração da Pessoa Portadora de Deficiência - Corde, institui a tutela jurisdicional de interesses coletivos ou difusos dessas pessoas, disciplina a atuação do Ministério Público, define crimes, e dá outras providências.

BRASIL. Ministério da Educação. Secretaria de Educação Especial. Política Nacional de Educação Especial. Brasília: MEC/SEESP, 1994.

BRASIL. Lei nº 9.394 de 20 de dezembro de 1996. Estabelece as diretrizes e bases da educação nacional.

BRASIL. Decreto no 3.298, de 20 de dezembro de 1999. Regulamenta a Lei no 7.853, de 24 de outubro de 1989, dispõe sobre a Política Nacional para a Integração da Pessoa Portadora de Deficiência, consolida as normas de proteção, e dá outras providências.

BRASIL. Lei n 13.005, de 25 de junho de 2014. Aprova o Plano Nacional de Educação - PNE e dá outras providências.

BARBOSA, M. O.; FUMES, N. L. F. Pontos e contrapontos no universo do atendimento educacional especializado para educandos com transtorno do espectro autista. Revista Iberoamericana de Estudos em Educação, v. 11, n. esp. 1, 2016. Disponível em: http://seer.fclar.unesp.br/ iberoamericana/article/view/8567/5748. Acesso em: 2 maio 2015.

CARVALHO, R. E. Educação Inclusiva: com os pingos nos “is”. Porto Alegre: Editora Mediação, 2011.

FARAH, M. F. S. Administração Pública e Política Pública. Revista de Administração Pública (RAP), v. 45, p. 813-836, 2011. 
KINGDON, J. W. Agendas, Alternatives, and Public Policies. New York: HarperCollins, 1995. 2nd ed. Cap. 9 “Wrapping things up - session Agenda setting”.

MATOS, S. N.; MENDES, E. G. A proposta de inclusão escolar no contexto nacional de implementação das políticas educacionais. Práxis Educacional (On-line), v. 10, p. 33-59, 2014. Disponível em: http://periodicos.uesb.br/index.php/praxis/article/ viewFile/2889/2571. Acesso em: 4 nov. 2016.

\section{MANTOAN, M. T. E. Inclusão escolar: o que é? Por} quê? Como fazer? São Paulo: Editora Summus, 2015.

MITTLER, P. Em direção à prática Inclusiva (Cap.8). In: Educação Inclusiva: Contextos Sociais. Porto Alegre: Artmed, 2003.

OLIVEIRA, A. A. S.; DRAGO, S. L. . A gestão da inclusão escolar na rede municipal de São Paulo: algumas considerações sobre o Programa Inclui. Ensaio: aval. pol. públ. Educ., Rio de Janeiro, v. 20, n. 75, p. 347-372, abr./jun. 2012.

SAAD, S. N. A pessoa com deficiência e a sociedade: o enfoque sociológico abre caminho para a inclusão. In: Preparando o Caminho da Inclusão. São Paulo: Vetor, 2003.

SAMPAIO, C.; SAMPAIO, S. M. Educação Inclusiva: 0 professor mediando para a vida. Salvador: EDUFBA, 2009.

SANCHES, I.; TEODORO, A. Da integração à inclusão escolar: cruzando perspectivas e conceitos. Porto: Revista Lusófona de Educação, n. 8, 63-83, 2006.

SÃO PAULO (Município). Decreto Municipal no 45.415, de 18 de outubro de 2004. Estabelece diretrizes para a Política de Atendimento às Crianças, Adolescentes, Jovens e Adultos com necessidades educacionais especiais no sistema municipal de ensino. Diário Oficial do Município de São Paulo, de 19 de outubro de $2004 a$.
SÃO PAULO (Município). Portaria n 5.718, de 17 de dezembro de 2004. Regulamenta o Decreto 45.415/04. Diário Oficial do Município de São Paulo, 18 de dezembro de 2004b.

SÃO PAULO (Município). Decreto Municipal n ${ }^{\circ}$ 51.778, de 14 de setembro de 2010. Institui a política de Atendimento de Educação Especial, por meio do programa Inclui, no âmbito da Secretaria Municipal de Educação. Diário Oficial do Município de São Paulo, 15 de setembro de 2010.

SÃO PAULO (Município). Decreto Municipal $n^{0}$ 52.785, de 10 de novembro de 2011. Cria as Escolas Municipais de Educação Bilíngue Para Surdos EMEBS. Diário Oficial do Município de São Paulo, 11 de novembro de 2011a.

SÃO PAULO (Município). Portaria n 5.707, 12 de dezembro de 2011. Regulamenta o Decreto 52.785/10. Diário Oficial do Município de São Paulo, 13 de dezembro de 2011b.

SÃO PAULO (Município). Portaria n² 2.963, 15 de maio de 2013. Organiza o quadro de Auxiliares de Vida Escolar - AVEs e de Estagiários de Pedagogia, em apoio a Educação Inclusiva e especifica as suas funções. Diário Oficial do Município de São Paulo, 16 de maio de 2013.

SÃO PAULO (Município). Portaria nº 6.566, 24 de novembro de 2014. Dispõe sobre a implantação e implementação do Núcleo de Apoio e Acompanhamento para a Aprendizagem - Naapa, nas Diretorias Regionais de Educação da Secretaria Municipal de Educação, e dá outras providências. Diário Oficial do Município de São Paulo, 25 de novembro de 2014.

SÃO PAULO (Município). Portal Prefeitura de São Paulo, Secretaria Municipal de Educação - SME/SP. Disponível em: http://portal.sme.prefeitura.sp.gov.br. Acesso em: 2 maio 2015 
SÃO PAULO (Município). Planeja SAMPA. Disponível em: http://planejasampa.prefeitura.sp.gov.br/metas/ meta/54/. Acesso em: 2 maio 2016.

SILVA, L. M. G. Educação Especial e a Inclusão Escolar sob a perspectiva legal. Simpósio Internacional 0 Estado e as Políticas Educacionais no Tempo Presente, 1, 2008, Uberlândia. Anais [...], 2008. Disponível em: http://www. simposioestadopoliticas.ufu.br/imagens/anais/pdf/ BP05.pdf. Acesso em: 10 nov. 2016.
SOUZA, C. Políticas públicas: uma revisão da literatura. Sociologia, Porto Alegre, ano 8, n. 16, p. 20-45, jul./dez. 2006.

SOUZA, J.; KANTORSKI, L. P.; LUIS, M. A. V. Análise documental e observação participante na pesquisa em saúde mental. Revista Baiana de Enfermagem: Salvador, v. 25, n. 2, p. 221-228, maio/ago. 2011. 
